\title{
Carcinoma of the lung and diffuse interstitial pulmonary fibrosis
}

\author{
B. FOX AND R. A. RISDON \\ From the Department of Morbid Anatomy, Charing Cross Hospital Medical School, London
}

SYNOPSIS The clinical and histopathological findings are presented in two cases of diffuse interstitial pulmonary fibrosis in which carcinoma of the lung developed. In one case with rheumatoid arthritis and diffuse interstitial pulmonary fibrosis there was 'malignant pulmonary adenomatosis', an association which does not appear to have been reported before. In the second case idiopathic diffuse interstitial pulmonary fibrosis was complicated by large cell anaplastic carcinoma of the lung.

It is suggested that in both cases the development of carcinoma of the lung was a complication of the epithelial hyperplasia and scarring that occurs in diffuse interstitial pulmonary fibrosis.

It is also suggested that carcinoma found in the main bronchi in patients with diffuse interstitial pulmonary fibrosis should not be regarded as coincidental unless careful search has excluded a carcinomatous change in the periphery of the scarred lungs.

There are very few reports of carcinoma of the lung in diffuse interstitial pulmonary fibrosis; most of those that have been reported concerned the occasional association of carcinoma due to progressive systemic sclerosis (scleroderma) (Zatuchni, Campbell, and Zarafonetis, 1953; Jonsson and Houser, 1956; Richards and Milne, 1958; Collins, Darke, and Dodge, 1958; Caplan, 1959). Scadding's (1960) series of 26 cases of diffuse interstitial pulmonary fibrosis included one in which histological examination of the lungs showed changes 'closely resembling alveolar cell carcinoma' and another in which an unequivocal bronchial carcinoma was found. Livingstone, Lewis, Reid, and Jefferson (1964) found a small peripheral bronchial carcinoma in one of 45 cases of diffuse interstitial pulmonary fibrosis.

As far as we are aware there has been only one previous report of carcinoma of the lung developing in a patient with diffuse interstitial pulmonary fibrosis associated with rheumatoid arthritis (Lee and Brain, 1962). This growth was an adenocarcinoma but there was no detailed histological description; it was regarded as an incidental finding.

We report a further case of carcinoma of the lung in a patient with diffuse interstitial pulmonary fibrosis and rheumatoid arthritis, and a case of idiopathic diffuse interstitial pulmonary fibrosis with anaplastic carcinoma which had arisen in the

Received for publication 29 November 1967. scarred lung and metastasized to hilar lymph nodes. The clinical, histological, and post-mortem findings in these two cases are presented. The relationship between carcinoma of the lung and diffuse interstitial pulmonary fibrosis is discussed: it is suggested that the carcinoma is a sequel to the scarring and epithelial hyperplasia which occurs in the lung in this condition.

\section{CASE REPORTS}

CASE 1 A man, aged 61 years, was first seen in 1962 with a three-year history of painful, swollen joints. $X$-ray examination of the hands and feet showed typical changes of rheumatoid arthritis. The differential agglutination titre was $1: 256$. The chest was not examined radiologically at this time. He was treated at first with salicylates and wax baths, and was then given methyl prednisolone (4 $\mathrm{mg}$ per day) which he continued to take for the rest of his life.

He was seen again in March 1966 because of bronchitis during the three preceding winters. $X$-ray examination of the chest showed an opacity in the lower lobe of the right lung with some segmental collapse. Bronchoscopy showed compression of the right lower lobe bronchus. The right lower and middle lobes and the posterior segment of the right upper lobe were removed (Mr A. R. Makey). The postoperative course was complicated by bronchopneumonia and episodes of pulmonary embolism. The patient died of these complications 31 days after the operation.

Surgical specimen (from right lung) In the lower lobe there were two separate lobulated grey-white 486 


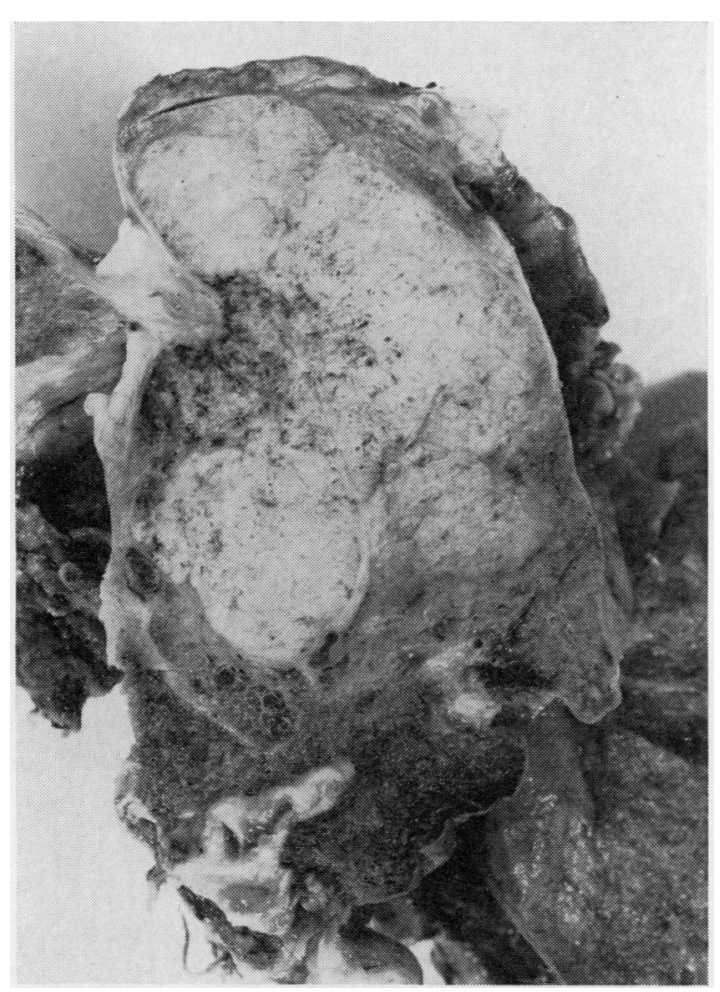

FIG. 1. Case 1: lower lobe of right lung: lobulated tumour and thin-walled cysts.

tumours: one $(11.5 \times 7.5 \times 4.5 \mathrm{~cm})$ extended to the pleural surfaces and the other $(2 \times 2.5 \times 3 \mathrm{~cm})$ was near the hilum (Fig. 1). Collections of thin-walled cysts (up to $1.0 \mathrm{~cm}$ diameter) were scattered diffusely throughout the lung.

Histological examination of the tumour showed the appearances of 'malignant pulmonary adenomatosis'. The tumour was composed of large, pleomorphic columnar and polygonal cells lining air spaces, and in places forming papillary projections (Fig. 2). There were occasional mitotic figures some of which were atypical. In some areas there were the changes of 'benign pulmonary adenomatosis' as described by Spencer and Raeburn (1956) (Fig. 3) with spaces lined by regular columnar epithelium which in places merged with the malignant areas. In the rest of the lung there were cysts and alveolar spaces, lined by flattened, tall ciliated, and mucus-secreting columnar epithelium, with occasional foci of squamous metaplasia. Many of the spaces contained macrophages and fibrin. There were areas of interstitial fibrosis, elastosis, and occasional excess smooth muscle fibres with focal and diffuse infiltration by lymphocytes, plasma cells, histiocytes, and neutrophils. Many arteries showed fibroelastic hyperplasia of the intima and media (Fig. 4).

Necropsy Both wrists and hands showed rheumatoid deformities. The main pulmonary arteries and many of their branches were occluded by antemortem thrombi and there were associated pulmonary infarcts. There was thrombosis of the calf veins.

Both lungs were firm and contained scattered thinwalled cysts (up to $1 \mathrm{~cm}$ in diameter). No evidence of residual or metastatic carcinoma was found, and there was no primary carcinoma elsewhere in the body.

Histological examination of the lungs showed diffuse interstitial pulmonary fibrosis, acute suppurative bronchopneumonia, pulmonary infarction, and organizing thrombi in pulmonary arteries. No carcinoma was found in sections of the lungs, and of the hilar and paratracheal lymph nodes.

The final diagnoses were diffuse interstitial pulmonary fibrosis, with 'malignant' and 'benign pulmonary adenomatosis'; rheumatoid arthritis; pulmonary infarction; bronchopneumonia.

CASE 2 An electric cable joiner, aged 54 years, was first seen in August 1964 with a history of increasing shortness of breath for four months, and an occasional cough with small amounts of mucoid sputum. On exertion he became breathless and had a tight sensation across his chest. He became dysponeic and cyanosed with the slightest exertion. His fingers were clubbed and there were numerous rales at both lung bases. $X$-ray examination of the chest showed diffuse mottling in both lower lobes. He was afebrile. There was no clinical evidence of rheumatoid arthritis, scleroderma, or other disease.

Lung function studies showed a vital capacity of 1,700 $\mathrm{ml}$ with $\mathrm{FEV}_{1}$ of $1,100 \mathrm{ml}$. Carbon monoxide diffusion was $5.9 \mathrm{ml} / \mathrm{min} / \mathrm{mmHg}$ (at minute ventilation $9.61 . / \mathrm{min}$ ) and $6.5 \mathrm{ml} / \mathrm{min} / \mathrm{mmHg}$ (at minute ventilation of 33.3 1./min). The $p \mathrm{CO}_{2}$ was $40 \mathrm{mmHg}$ at rest and $25 \mathrm{mmHg}$ on exertion. Total serum proteins were $8.7 \mathrm{~g} / 100 \mathrm{ml}$ (albumin $3.8 \mathrm{~g} / 100 \mathrm{ml}$ and globulin $4.9 \mathrm{~g} / 100 \mathrm{ml}$ ). Serum protein electrophoresis showed prominent $\mathrm{alpha}_{2}$ and beta globulin bands. No pathogenic organisms were cultured from his sputum. Differential agglutination titre and Latex test were negative.

A biopsy of the right lower lobe of the lung was made and this confirmed the diagnosis of diffuse interstitial pulmonary fibrosis. He was treated with prednisolone $(40 \mathrm{mg} /$ day) but there was no improvement in his condition, and he died at his home in December 1964.

Surgical specimen Histological examination of a piece of lung $2.5 \times 2.0 \times 0.8 \mathrm{~cm}$ showed dense interstitial fibrosis and elastosis. There were irregularly shaped alveolar spaces lined by cuboidal, columnar and flattened epithelium, and cystic spaces mainly lined by flattened epithelium. Some alveolar spaces were lined by large, irregularly shaped epithelial cells, which resembled the carcinoma cells seen in the lungs and lymph nodes at necropsy. There was marked infiltration by plasma cells, lymphocytes, histiocytes, and neutrophils; occasional eosinophils were present. The pulmonary arteries showed marked fibroelastic hyperplasia of the intima and media (Fig. 5).

Necropsy (36 hours after death) The larynx, trachea, and bronchi contained mucopus. Both lungs were firm and distended. The pleural surfaces were nodular and 
FIG. 2.

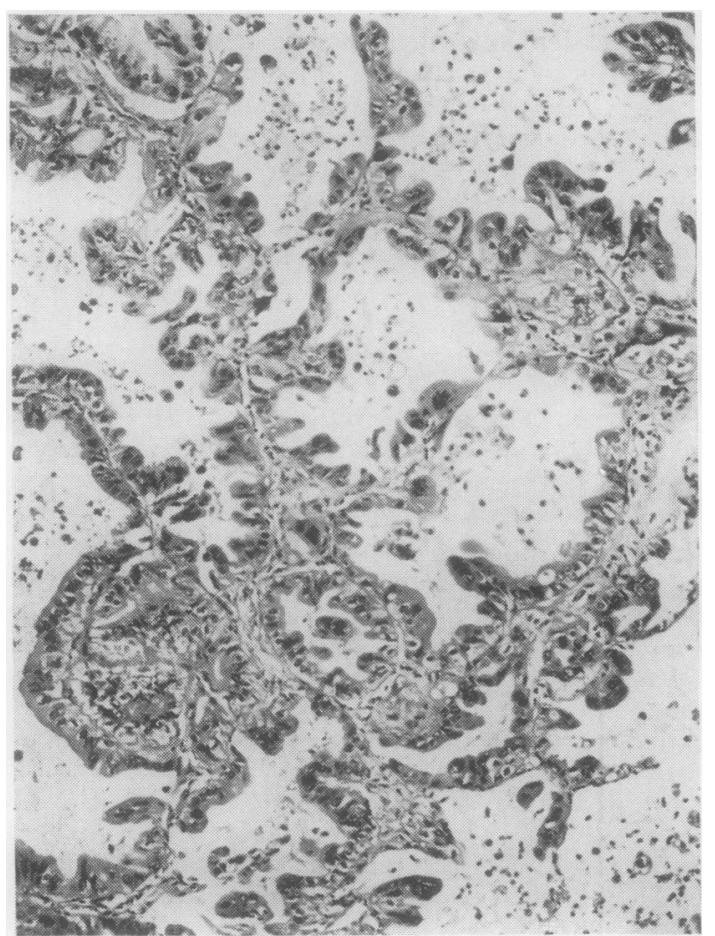

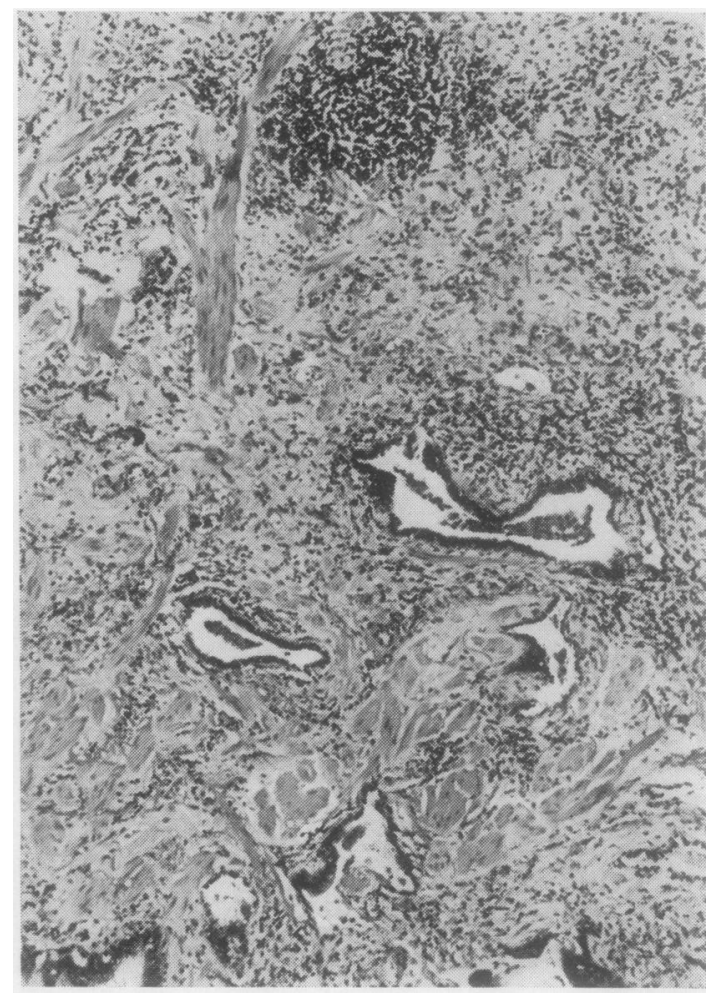

FIG. 4.

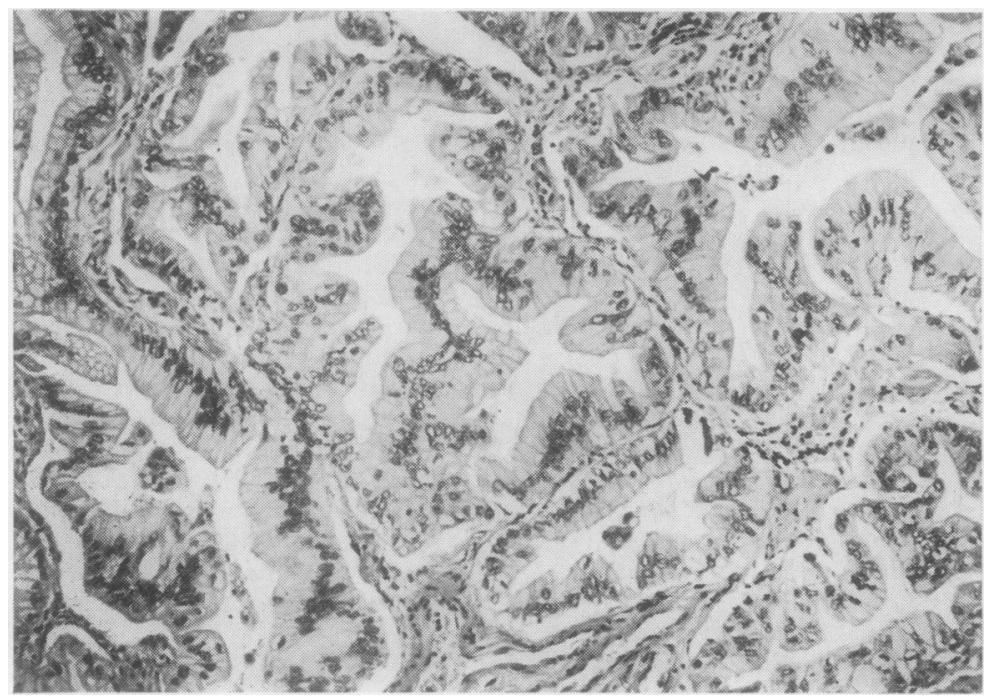

FIG. 2. Case 1: 'malignant pulmonary adenomatosis'. Haemalum and eosin $\times 74$.

FIG. 3. Case 1: 'benign pulmonary adenomatosis.' Haemalum and eosin $\times 74$.

FIG. 4. Case 1: middle lobe of right lung. Diffuse interstitial pulmonary fibrosis. Haemalum and eosin $\times 42$.

FIG. 3 . 

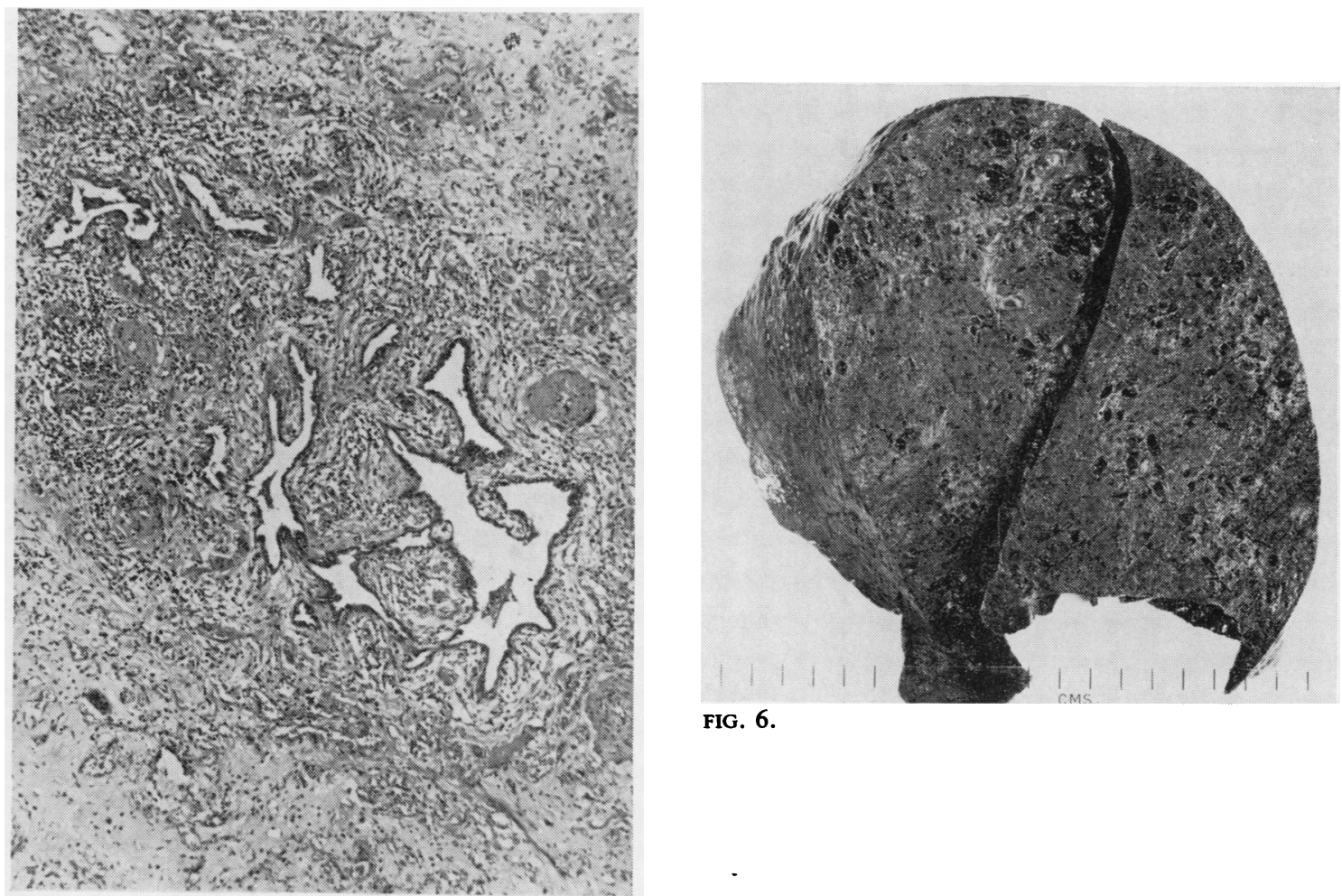

FIG. 6.

FIG. 5 .

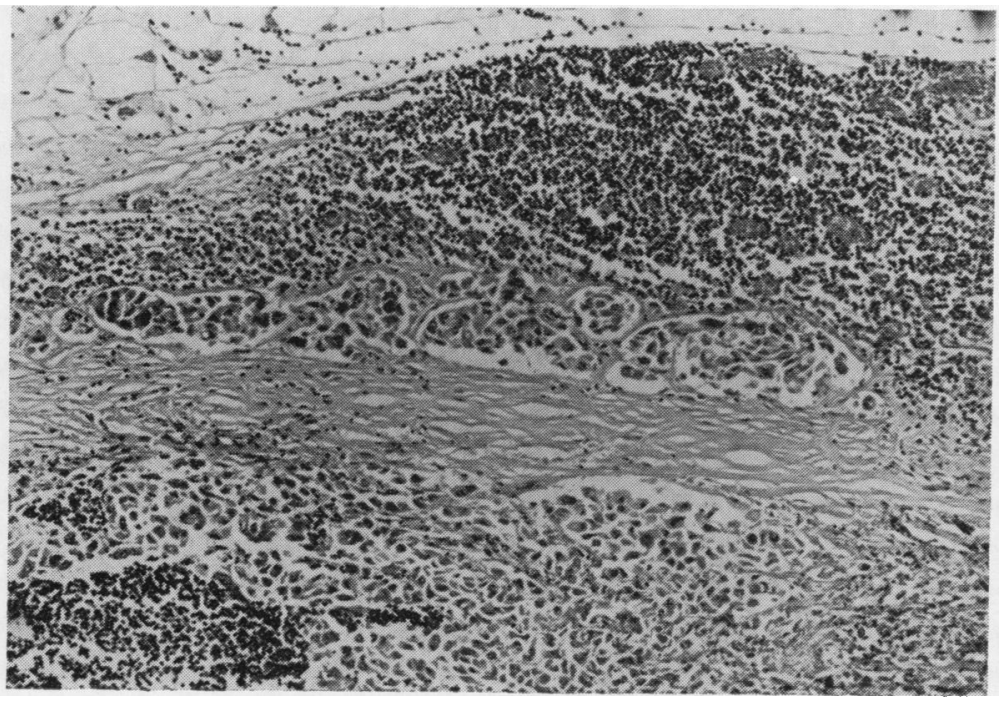

FIG. 5. Case 2: biopsy of lower lobe of right lung. Diffuse interstitial pulmonary fibrosis. Haemalum and eosin $\times 45$.

FIG. 6. Case 2: cut surface of left lung: diffuse interstitial pulmonary fibrosis with numerous cysts mainly in the upper lobe.

FIG. 7. Case 2: lymph node from hilum of right lung infiltrated by large cell anaplastic carcinoma. Haemalum and eosin $\times 75$.

FIG. 7. 


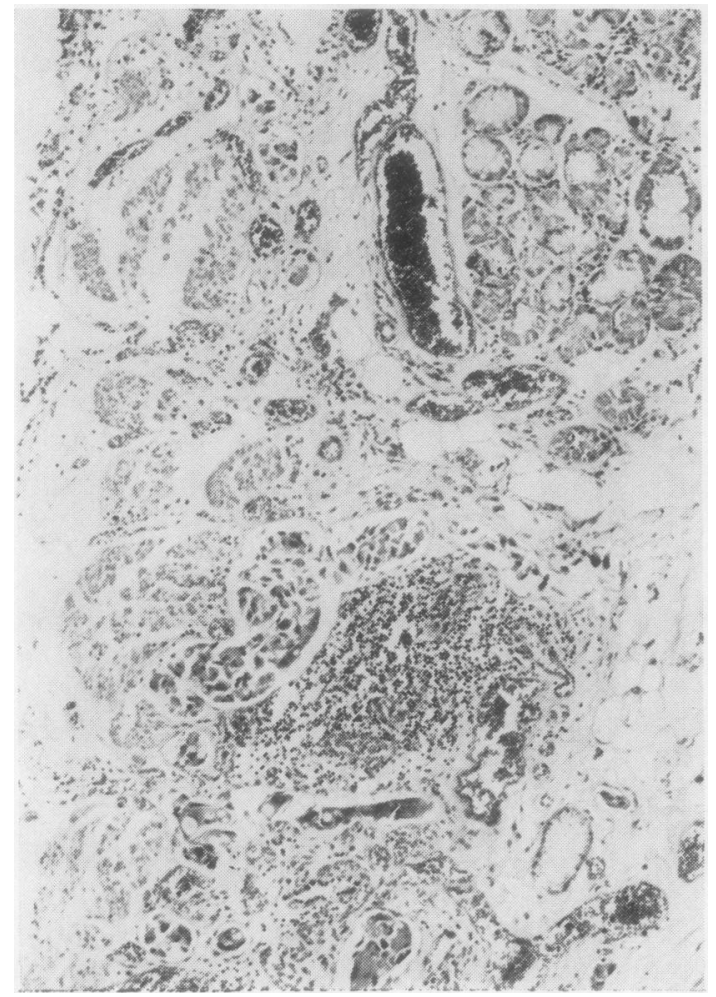

FIG. 8.

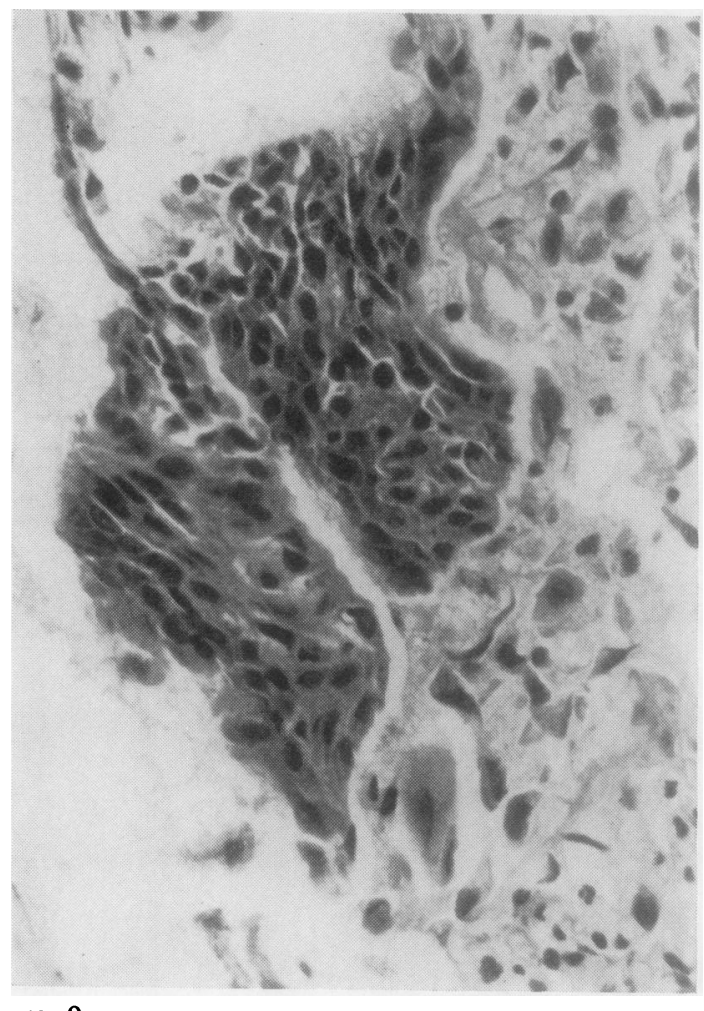

FIG. 9.

FIG. 8. Case 2: large cell anaplastic carcinoma in bronchial lymphatics. Haemalum and eosin $\times 39$.

FIG. 9. Case 2: a clump of cells in the wall of an air space in the right lung, resembling the anaplastic carcinoma in the bronchial lymphatics. Haemalum and eosin $\times 300$.

throughout the cut surfaces, especially in the upper lobes and in the apex of the right lower lobe, there were smooth-walled cysts varying in size from less than 0.2 to $2.5 \mathrm{~cm}$ in diameter (Fig. 6).

There were no other significant abnormalities apart from soft, enlarged lymph nodes at the hilum of each lung. As subsequent histological examination showed secondary carcinoma in the hilar lymph nodes from the right lung (see below), both lungs were carefully reexamined after fixation in formol-saline for the presence of a primary carcinoma. Blocks of tissue were taken for histological examination from any suspicious areas. In all 50 blocks were prepared from each of which numerous sections were examined.

Histological examination The lungs showed diffuse interstitial pulmonary fibrosis. In three lymph nodes from the hilum of the right lung and in the associated peribronchial and submucosal lymphatics there were deposits of large anaplastic carcinoma cells (Fig. 7 and 8). Lining occasional air spaces throughout both lungs there were clumps of cells which had a similar appearance to the carcinoma cells within the lymph nodes and bronchial lymphatics (Fig. 9). These changes were more marked in the right lung.
The final diagnoses were idiopathic diffuse interstitial pulmonary fibrosis and primary anaplastic large cell carcinoma of lung with metastasis in lymph nodes.

\section{DISCUSSION}

In both cases, the diagnosis of diffuse interstitial pulmonary fibrosis was made on surgical specimens and confirmed by post-mortem examination of the lungs. The changes were severe, corresponding to the $\mathcal{O}$ grade $\mathrm{V}$ changes of Livingstone et al. (1964).

In case 1 there is no doubt about the diagnosis of rheumatoid arthritis. There were characteristic clinical findings and strongly positive serological tests for rheumatoid factor. A variety of pulmonary lesions, including diffuse interstitial pulmonary fibrosis, $\stackrel{\oplus}{\stackrel{\oplus}{+}}$ may occur in patients with rheumatoid arthritis (Ellman and Ball, 1948; Cruickshank, 1959). The question arises whether this is fortuitous or whether $\mathbb{D}$ fibrosis develops as a result of rheumatoid disease $\frac{O}{\mathbb{D}}$ (British Medical Journal, leader, 1967). A causal $\varrho$ relationship based on an autoimmune mechanism 
has been suggested (British Medical Journal, leader, 1965 ) and evidence in support of this is the demonstration by Turner-Warwick and Doniach (1965) of various autoantibodies in sera from 48 patients with diffuse interstitial pulmonary fibrosis, 14 of whom had rheumatoid arthritis. Diffuse interstitial pulmonary fibrosis has also been described in association with a variety of other diseases of presumed autoimmune origin-systemic sclerosis (Hayman and Hunt, 1952), Sjörgen's syndrome (Bunim, 1961), systemic lupus erythematosis (Israel, 1953), and dermatomyositis (Hyun, Diggs, and Toone, 1962).

Although alveolar cell carcinoma (malignant pulmonary adenomatosis) has been described in cases of diffuse interstitial pulmonary fibrosis due to systemic sclerosis (Zatuchni et al., 1953; Jonsson and Houser, 1956; Richards and Milne, 1958; Collins et al., 1958; Caplan, 1959), there seems to be no previous report in a case with rheumatoid arthritis. There can be little doubt of the close association between diffuse interstitial pulmonary fibrosis and malignant pulmonary adenomatosis. It has been shown that in pulmonary fibrosis, from any cause, there may be epithelial hyperplasia which may progress to benign and malignant pulmonary adenomatosis (Raeburn and Spencer, 1953). A gradation of similar epithelial changes is present in case 1 and they have also been described in diffuse interstitial pulmonary fibrosis due to scleroderma (Collins et al., 1958; Caplan, 1959).

A diagnosis of idiopathic diffuse interstitial pulmonary fibrosis was made in case 2 as there was no evidence of other disease. It is interesting to note, however, that the patient had worked as an electric cable joiner for about 20 years and although there is no direct evidence it is just possible that the lung disease was in some way related to his occupation. Electric cable joining entails the use of heated flux, sometimes in enclosed spaces, and it may be that under these circumstances harmful volatile or particulate substances would be inhaled. Although no localized carcinoma was found in this case after careful macroscopic and microscopic examination of both lungs, there was marked epithelial hyperplasia throughout the right lung, and similar but less severe changes in the left lung. The groups of cells in many of these areas were histologically identical to the secondary carcinoma in the hilar lymph nodes. It would not be possible to make a definite diagnosis of malignancy on the appearance in the lung alone but the presence of the secondary deposits confirms its carcinomatous nature. There is probably a causal relationship between the epithelial changes and interstitial fibrosis. Although adenocarcinoma is the commonest type of cancer developing in fibrous scars, oat cell and squamous carcinoma have also been described (Stewart and Allison, 1943; Raeburn and Spencer, 1953; Meyer and Liebow, 1965). It is of interest to note that in case 1, apart from the changes of pulmonary adenomatosis, there were also foci of squamous metaplasia. It is therefore probable that not only alveolar cell carcinoma but also other types of pulmonary carcinoma may occur in diffuse interstitial pulmonary fibrosis. In case 2 the growth in the hilum, which was due to lymphatic spread from the lung, was very closely related to the main bronchus and histologically had the appearances of anaplastic bronchial carcinoma. Raeburn and Spencer (1953) have suggested that many centrally situated bronchial carcinomas which appear to have arisen from the large bronchi may in fact have originated by lymphatic spread from a tiny neoplasm in the periphery of the lung.

Bronchial carcinomas have been observed in cases of diffuse interstitial pulmonary fibrosis and have been regarded as a coincidental finding (Scadding, 1960). It is probable, however, that some of these tumours, which apparently arise from the bronchi, may be the result of metastatic spread from a small undiscovered primary carcinoma in the fibrotic lungs.

We wish to thank Professor W. St. C. Symmers and Dr N.S. Plummer for their help in the preparation of this paper. Our thanks are also due to the technical staff of the Department of Morbid Anatomy, and to the photographic department of Charing Cross Hospital Medical School for the photomicrographs. We are indebted to Dr P. B. S. Fowler and Mr A. R. Makey for permission to use the clinical notes of these cases, and to Dr C. McKerron for helpful discussion on the clinical findings.

\section{REFERENCES}

British Medical Journal (Leading Article) (1965). Brit. med. J., 2, 431. (Leading Article) (1967). Ibid., 1, 186.

Bunim, J. J. (1961). Ann. rheum. Dis., 20, 1.

Caplan, H. (1959). Thorax, 14, 89.

Collins, D. H., Darke, C. S., and Dodge, O. G. (1958). J. Path. Bact., 76, 531 .

Cruickshank, B. (1959). Brit. J. Dis. Chest, 53, 226.

Ellman, P., and Ball, R. E. (1948). Brit. med. J., 2, 816.

Hayman, L. D., and Hunt, R. E. (1952). Dis. Chest, 21, 691.

Hyun, B. H., Diggs, C. L., and Toone, E. C., Jr (1962). Ibid., 42, 449.

Israel, H. L. (1953). Amer. J. med. Sci., 226, 387.

Jonsson, S. M., and Houser, J. M. (1956). New Engl. J. Med., 255, 413.

Lee, F. I., and Brain, A. T. (1962). Lancet, 2, 693.

Livingstone, J. L., Lewis, J. G., Reid, L., and Jefferson, K. E. (1964). Quart. J. Med., 33, 71.

Meyer, E. C., and Liebow, A. A. (1965). Cancer (Philad.), 18, 322. Raeburn C., and Spencer, H. (1953). Thorax, 8, 1.

Richards, R. L., and Milne, J. A. (1958). Ibid., 13, 238.

Scadding, J. G. (1960). Brit. med. J., 1, 443.

Spencer, H. and Raeburn, C. (1956). J. Path. Bact., 71, 145.

Stewart, M. J., and Allison, P. R. (1943). Ibid., 55, 105.

Turner-Warwick, M., and Doniach, D. (1965). Brit. med. J., 4, 886.

Zatuchni, J., Campbell, W. N., and Zarafonetis, C. J. D. (1953). Cancer(Philad.), 6, 1147. 